\title{
Endoscopic Profile of Children with Colorectal Polyps Attending a Tertiary Centre
}

\author{
Upadhyay S1, Sharma A², Sapkota $\mathrm{P}^{3}$
}

\begin{abstract}
Introduction: Polyps are the most common causes of colorectal bleeding in children. This report describes an endoscopic profile of children with colorectal polyps at Nepal Medical College and Teaching Hospital. Materials and Methods: This prospective study was conducted in children who were evaluated for painless lower $\mathrm{Gl}$ bleed who underwent colonoscopyin Nepal Medical College, Kathmandu, Nepal from November 2014 to May 2017. Patients with age of presentation less than or equal to 18 years and diagnosed endoscopically to have colorectal polyp were included in the study and were followed up till histopathological reports. Results:A total of 35children with colorectal polyps were identified. Twenty-three (65.7\%) patients were males and $12(35.3 \%)$ were females, male/ female ratio being 2.1: 1 . The mean age of the patients at the time of diagnosis was 5.2 years $( \pm 3.7$ years), (range 1.3-13.5) years. The duration of bleeding varied from 1 week to 3 years (mean 13 months), and $23(67.6 \%)$ children were symptomatic for more than 12 months. All patients $(100 \%)$ had painless rectal bleed, eight $(23.5 \%)$ presented with anaemia and two of them requiring blood transfusion before the procedure (< $7.0 \mathrm{gm} / \mathrm{dl}$ ), seven $(20.5 \%)$ patients had blood and mucus in stools, six $(17.6 \%)$ of them had rectal mass (prolapsed polyp). Conclusion:Juvenile colorectal polyps are the most common cause of painless rectal bleeding in young children. In the majority, these are solitary, occur in the rectosigmoid. Delay in treatment may cause anaemia.Colonoscopic snare polypectomy is a safe therapeutic modality.
\end{abstract}

Key words: Gastrointestinal, Juvenile rectal polyp

\section{Introduction}

D olyps are the most common causes of colorectal bleeding in children ${ }^{1,2}$. Intermittent indolent rectal bleeding is the main symptom of colonic polyps. Polyp is a benign rounded hamartoma of the large bowel. Juvenile polyp may be present in large numbers in children and is commonly associated with rectal bleeding ${ }^{3}$. Isolated juvenile polyp is the most frequent kind of polyp identified in children. 'Juvenile' refers to the histological type of polyp and not the age of onset of the polyp ${ }^{3}$. Juvenile polyps are generally thought to be hamartomatous lesion with little malignant potential. They have been
${ }^{1}$ Dr. Satyam Upadhyay, MBBS. MD, Fellowship (Paediatric gastroenterology), Assistant Professor, ${ }^{2}$ Dr. Anna Sharma, MBBS. MD, Assistant Professor, ${ }^{3} \mathrm{Dr}$. Pabitra Sapkota, MBBS, MD Resident. All from the Department of Paediatrics, Nepal Medical College and Teaching Hospital, Attarkhel, Jorpati, Kathmandu, Nepal.

\section{Address for correspondence}

Dr. Satyam Upadhyay, Assistant Professor, Department of Paediatrics,

Nepal Medical College and Teaching Hospital, Attarkhel, Jorpati,

Kathmandu, Nepal

Tel no: +9779841264617

E-mail: rimalsatyam@gmail.com

Acknowledgements: We would like to acknowledge our sincere thanks to all the staff of endoscopy unit.

Funding: Nil

Conflict of Interest: None

Permission from IRB: Yes

\section{How to cite}

Upadhyay S, Sharma A, Sapkota P. Endoscopic Profile of Children with Colorectal Polyps Attending a Tertiary Centre. J Nepal Paediatr Soc 2017;37(2):134-137.

doi: http://dx.doi.org/10.3126/jnps.v37i2.17715

This work is licensed under a Creative Commons Attribution 3.0 License. 
reported to be solitary and recto-sigmoid in location in $80-90 \%$ of cases $^{4,5}$. It is difficult to differentiate the hyperplastic polyps and adenomatous ones without histological examinations. Moreover, repetitive bleeding may lead to iron deficiency anaemia. Therefore, early detection and polypectomy are necessary for all colonic polyps ${ }^{6,7}$. Fiberoptic colonoscopy is a routine modality for the diagnosis and treatment of colorectal polyps in paediatric population ${ }^{8}$. Although there have been clinical studies on colonic polyps in children in India ${ }^{5}$, there is dearth of data because of lack of paediatric colonoscopy facility in Nepal. The aim of this study was to describe the endoscopic profile of children with colorectal polyps at Nepal Medical College and Teaching Hospital.

\section{Materials and Methods}

This prospective study was conducted in children who were evaluated for painless lower Gl bleed who underwent colonoscopyin Nepal Medical College, Kathmandu, Nepal from November 2014 to May 2017. Patients with age of presentation less than or equal to 18 years and diagnosedendoscopically to have colorectal polyp were included in the study. Bowel preparation was done with polyethylene glycol. In accordance with the institutional protocol, endoscopic procedures on patients were performed under sedation (Midazolam $0.1 \mathrm{mg} / \mathrm{kg}$ along with Ketamine $1 \mathrm{mg} / \mathrm{kg}$ ) administered by anaesthesiologists/paediatrician. Procedures were performed once patients were sedated after monitoring of vital signs and oxygen saturation. Colonoscopy was performed with Karl Storzpediatric video colonoscope (outer diameter $11.2 \mathrm{~mm}$, working channel $3.4 \mathrm{~mm}$ ). Colonoscopic polypectomy was performed with the loop snare technique.

The excised polyp was retrieved with a tripod basket or a net catheter and subjected to a histopathological examination. The data related to age, gender, clinical presentation, size, number, location, and histopathology of colorectal polyps were collected and analyzed. Polyps were anatomically categorized as left colonic (if found in the splenic flexure and distal colon), right colonic (if found proximal to the splenic flexure), and pan-colonic (if found both distal and proximal to the splenic flexure).

Procedures were performed only after patients parents or legal guardians had signed informed consent forms.Data obtained from the patient population were then analysed and studied using SPSS (Version 16) statistical program.

\section{Results}

A total of 35 children with colorectal polyps were identified. Twenty-three $(65.7 \%)$ of the patients were males and 12 (35.3\%) were females, (Fig 1) the male/female ratio being 2.1: 1 . The mean age of the patients at the time of diagnosis was 5.2 years $( \pm 3.7$ years, range 1.3-13.5) years. Table 1 outlines the spectrum of presenting symptoms. Painless rectal bleed (haematochezia)was the most common symptom and it varied from streaks of blood in stools to passage of drops of fresh blood after defecation. The duration of bleeding varied from 1 week to 3 years (mean 13 months), and $23(67.6 \%)$ children were symptomatic for more than 12 months.

Table 1: Spectrum of Presenting Symptoms

\begin{tabular}{clcc}
\hline S.N & Symptoms & Number & Percentage \\
\hline 1 & Painless rectal bleed & 34 & $100 \%$ \\
\hline 2 & Anaemia & 8 & $23.5 \%$ \\
\hline 3 & $\begin{array}{l}\text { Anal mass/(Prolapsed } \\
\text { polyp) }\end{array}$ & 6 & $17.6 \%$ \\
\hline $\begin{array}{l}\text { Blood and mucous in } \\
\text { stool }\end{array}$ & 7 & $20.5 \%$ \\
\hline
\end{tabular}

Apart from painless rectal bleed, eight (23.5\%) presented with anaemia and two of them requiring blood transfusion preoperatively ( $<7.0 \mathrm{gm} / \mathrm{dl})$, seven $(20.5 \%)$ patients had blood and mucus in stools, six (17.6\%) of them had rectal mass (prolapsed polyp). Twenty two patients $(64.7 \%)$ had a solitary polyp and thirteen patients $(35.3 \%)$ had multiple polyps. Two polyps were found in seven patients $(20.5 \%)$, three polyps in three patients $(0.08 \%)$, four polyps in two patients $(0.05 \%)$, and multiple polyps in one patient. Majority of the polyp were pedunculated $53(90 \%)$ and $6(10 \%)$ were sessile.

Table 2: Location of Polyp

\begin{tabular}{clc}
\hline S.N & Location & Number of Polyp (\%) \\
\hline 1 & Rectum & $38(62.2 \%)$ \\
\hline 2 & Sigmoid & $16(30.1 \%)$ \\
\hline 3 & Descending Colon & $3(5.6 \%)$ \\
\hline 4 & Transverse Colon & $1(1.8 \%)$ \\
\hline & Total & $\mathbf{1 0 0 \%}$ \\
\hline
\end{tabular}

Table 2 summarizes the location of polyp. Of all polyps found, thirty three $(62.2 \%)$, the largest number of all, were located in rectum. Table 3 outlines the size of polyp. The size of the polyps varied in the range between $4 \mathrm{~mm}$ and $30 \mathrm{~mm} .41(77.3 \%)$, the largest number, had diameter between $10 \mathrm{~mm}-19 \mathrm{~mm}$.

Table 3: Size of Polyp

\begin{tabular}{ccc}
\hline S.N & Diameter $(\mathbf{m m})$ & Number of Polyp (\%) \\
\hline 1 & $0-10 \mathrm{~mm}$ & $8(13.6 \%)$ \\
\hline 2 & $10-19 \mathrm{~mm}$ & $47(79.7 \%)$ \\
\hline 3 & $20-30 \mathrm{~mm}$ & $4(6.7 \%)$ \\
& Total & $\mathbf{1 0 0 \%}$ \\
\hline
\end{tabular}


All polyps in the study were excised using the loop snare technique. Pre-operative submucosal salineepinephrine injection was used in $6(11.3 \%)$ sessile polyps. We also analysed the histopathological reports. 34 patient's histopathological reports were consistent with Juvenile rectal polyp.Histologically, juvenile polyp had adistinctive cystic architecture, mucus-filled glands, a prominentlamina propriawith or without infiltration with inflammatory cells. One of the patients had a history of polypectomy in other health care facility, hyperpigmentedmacules on the lips and oral mucosa and had multiple polyps. Histopathology of polyp revealed hamartomatous polyp with arborisation of muscularis mucosae covered with normal villithus confirming theclinical diagnosis of PeutzJeghers Syndrome.

\section{Discussion}

The most common cause of painless colorectal in children in our study were benign juvenile polyps. The mean age in our study was 5.2 years old, and was similar to that in several previous reports ${ }^{9,10}$ but was younger than reported in the other studies ${ }^{11,12}$ The male to female ratio in this study was $2.1: 1$, which was similar with previous studies ${ }^{11,12,13}$. The reason for this gender bias is not well understood thus far.

The clinical spectrum of our children with polyps differs from other series ${ }^{5,14,15}$. All 35(100\%) children had haematochezia with or without other symptoms, the mean duration of bleeding per rectum (13 months) was much higher than reported previously by Cynamon and Pillai ${ }^{6,15}$

\section{References}

1. Gelb AM, Minkowitz S, Tresser M. Rectal and colonic polyps occurring in young people. NY State $J$ Med 1962; 62:513-18.

2. We JH, Park HS, Park JH. The role of colonoscopy in children with hematochezia. Korean $J$ PediatrGastroenterolNutr 2011;14:155-60

3. Durno CA. Colonic polyps in adolescent and children. Can J Gastroenterol 2007;21:233-39.

4. Jalihal A, Misra SP, Arvind AS, Kamath PS. Colonoscopic polypectomy in children. JPediatrSurg 1992;27:1220-22.

5. Poddar U, Thapa BR, Vaiphei K, Singh K. Colonic polyps: Experience of 236 Indian children. Am J Gastroenterol 1998;93:619-22.doi.org/10.1111/j.15720241.1998.176_b.x

6. Cynamon HA, Milov DE, Andres JM. Diagnosis and management of colonic polyps in children. $J$ Pediatr 1989;114:593-96
Eight $(23.5 \%)$ children presented with anaemia (haemoglobin<10.0 gm/dl) among our patients compared with other reported series ${ }^{6,16}$. Two of them required blood transfusionbecause their haemoglobin<8.0 gm/ $\mathrm{dl}$ before procto-sigmoidoscopic removal of polyps. The incidence of anaemia in our group is due to prolonged periods of rectal bleeding before they were brought for medical advice at our centre, as all $(100 \%)$ of children had bleeding per rectum with mean duration of 13 months. The delays in early referral resulted from public ignorance about the condition, frequency of dysentery, coexisting nutritional anaemia that is prevalent in our country ${ }^{17}$ and a lack of appreciation by family doctors about rectal polyps being one of the common causes of painless rectal bleeding. It is generally accepted that juvenile rectal polyps are usually solitary ${ }^{14,18,19}$ but recent reports suggest that multiple polyps do occur in $20-35 \%$ of the paediatric population ${ }^{6,20,21}$. In the present study, multiple polyps (maximum three) were found in twelve patients $(35.3 \%)$ patients. Recurrence has not been noted till this study was donewhereas $9-17 \%$ of recurrence has been noted in other major series ${ }^{6,21}$. Bleeding and perforation are the known complications following sigmoidoscopic removal of polyps. 5-14\% of complication has been noted in others ${ }^{15,22}$. No complication was noted in this study.

\section{Conclusion}

Juvenile colorectal polyps are the most common cause of painless rectal bleeding in young children. In the majority, these are solitary, occur in the recto sigmoid. Delay in treatment may cause anaemia.Colonoscopy snare polypectomy is a safe therapeutic modality.

7. Yashiro K, Tanabe M, lizuka B, Yaguchi T, Hasegawa K, Nagasako K. Polypectomy of a large juvenile polyp in the ascending colon. Endoscopy 1984;16:79-80.doi. org/10.1016/S0016-5107(98)70311-6

8. Park JH. Role of colonoscopy in the diagnosis and treatment of pediatric lower gastrointestinal disorders. Korean J Pediatr 2010;53:824-29.doi.org/10.3345/ kjp.2010.53.9.824

9. Byung G L, Sung H S, Young A L. Juvenile Polyp and Colonoscopic Polypectomy in Childhood. PediatrGastroenterolHepatolNutr2012;15:250-255. doi.org/10.5223/pghn.2012.15.4.250

10. Tam YH, Lee KH, Chan KW, Sihoe JD, Cheung ST. Colonoscopy in Hong Kong Chinese children. World J Gastroenterol 2010;16:1119-22.

11. Haghi MT, Monajemzadeh M, Motamed F, Moradi Tabriz H, Mahjoub F. Colorectal polyps: a clinical, endoscopic and pathologic study in Iranian children. Med PrincPract2009; 18:53-56. doi. org/10.1159\%2F000163047 
12. Thakkar K, Alsarraj A, Fong E, Holub JL, Gilger MA.Prevalence of Colorectal Polyps in Pediatric Colonoscopy. Dig Dis Sci 2012; 57: 1050-55.doi: 10.1007/s10620-011-1972-8.

13. Park KH, Park JH. Changes in pediatric gastrointestinal endoscopy: Review of a recent hospital experience. Korean J PediatrGastroenterolNutr 2007;10:20-27. doi:10.3345/kjp.2010.53.9.824

14. Latt TT, Nicholl R, Domizio P, Walker-Smith JA, Williams CB. Rectal bleeding and polyps. Arch Dis Child 1993; 69:144-47.

15. Pillai RB, ToliaV.Colonic polyps in children: frequently multiple and recurrent. ClinPediatr 1998;37:253-57.

16. Holgersen LO, Miller RE, ZintelHA.Juvenile polyps of the colon. Surgery 1978;69:288-93.

17. Mathema S, Shrestha A. Prevalence and Causes of Anemia in Six to Sixty Months Old Children: A Cross-
Sectional Study at Kathmandu Medical College and Teaching Hospital. J. Nepal PaediatrSoc 2013; 33:16365.doi.org/10.3126/jnps.v33i3.8847

18. Gupta SK, Fitzgerald JF, Croffie JM, Chong SK, Pfefferkorn MC, Davis MM et al. Experience with juvenile polyps in North American children: the need for pancolonoscopy. Am J Gastroenterol 96:1695-97. doi:10.1111/j.1572-0241.2001.03860.x

19. Jain CJT. Colorectal polyps in children: A 12-year review. Asian J Surgery 1995;18:118-21

20. Mestre JR. The changing pattern of juvenile polyps. Am $J$ Gastroenterol 1986; 81:312-14

21. Perisic V.N. Colorectal polyps: an important cause of rectal bleeding. Arch Dis Child 1987;62:188-89.

22. Euler AR, Seibert JJ. The role of Sigmoidoscopy, radiographs, and colonoscopy in the diagnostic evaluation of pediatric age patients with suspected juvenile polyps. J PediatrSurg 1981;16:500-02. 